\title{
Costs incurred by patients with oral potentially malignant disorders: is there a public health need for financial protection in India?
}

\author{
Jay R. Patel ${ }^{1}$ and Mihir P. Rupani ${ }^{*}$ (i)
}

\begin{abstract}
Objectives: Financial protection mechanisms are in place to overcome the costs of a few diseases in India. Our objective was to estimate the costs incurred due to Oral Potentially Malignant Disorders (OPMD) and to determine predictors of such costs.

Results: We found that the median (Interquartile range IQR) total costs of OPMD was Indian Rupees (INR) 500 (350-750), direct medical costs was INR 0 (0-50), direct non-medical costs was INR 150 (40-200) and indirect costs was INR 350 (250-500). The travel cost to attend the health facilities [INR 100 (40-150)] and the patient's loss of wages [INR 200 (150-400)] mainly accounted for the direct non-medical and indirect costs respectively. The median expenditure on smokeless and smoking forms of tobacco was INR 6000 (5400-7200) and INR 2400 (1800-3600) respectively. On multiple linear regression analysis, rural residence, belonging to below poverty line family, being a sole earner in the family, number of months since diagnosis and first visit at a private provider were found to be the significant predictors of total costs of OPMD. Financial protection mechanisms are needed for covering the direct non-medical and indirect costs. Early management of OPMD might mitigate the costs of OPMD.
\end{abstract}

Keywords: Oral precancerous lesions, Catastrophic costs, Oral cancer, Cash transfer schemes, Financial protection, Tobacco cessation

\section{Introduction}

Oral cancer is almost always preceded by clinically visible lesions that are noncancerous, to begin with, and which have therefore been termed oral potentially malignant disorders (OPMD) [1, 2]. Oral submucous fibrosis (OSMF), leukoplakia, erythroplakia, and lichen planus are the most commonly described OPMD [1, 2]. Globally,

\footnotetext{
*Correspondence: mihirrupani@gmail.com

${ }^{2}$ Division of Clinical Epidemiology, ICMR-National Institute

of Occupational Health (NIOH), Meghani Nagar, Ahmedabad, Gujarat 380016, India

Full list of author information is available at the end of the article Mihir P. Rupani: Affiliation during study period: Department of Community Medicine, Government Medical College Bhavnagar (Maharaja Krishnakumarsinhji Bhavnagar University), Near ST bus stand, Jail Road, Bhavnagar, Gujarat, 364001, India.
}

the burden of OPMD was reported to be $4.5 \%$, majorly contributed by OSMF (5\%) and leukoplakia (4\%) [3]. The highest prevalence rates were among the Asian (11\%) and South American/Caribbean populations (4\%), while the lowest was observed in North America (0.11\%) [3]. In India, a varying prevalence has been reported (4-58\%) [4-7], 10\% being the overall prevalence in western India [5].

Existing literature on costs of OPMD, none from India, focused on the costs borne by the healthcare facilities in treating these patients $[8,9]$. The average annual cost borne by a hospital for a patient with oral lichen planus was reported as $£ 400$ ( $\sim 36000$ Indian Rupees-INR) and the cost of laser surgery for OPMD was reported as $£ 998$ ( INR 89000$)$ during 2015-16 [8, 9]. Evidence is scarce on costs incurred by patients with OPMD and 
on the predictors associated with such costs in India. Evidence suggests that financial protection mechanisms are beneficial in reducing morbidity as well as mortality among cancer patients $[10,11]$. We conducted this study to estimate the costs incurred by patients for the care of OPMD and to determine the predictors of such costs in the Bhavnagar district of Gujarat (western India).

\section{Main text \\ Methods \\ Study design, setting and participants}

We conducted a cross-sectional study in the outpatient department (OPD) of the Otorhinolaryngology Department of Sir Takhtsinhji Hospital of Bhavnagar district of Gujarat from July-September 2019. The population of Bhavnagar district and Bhavnagar city as per census 2011 is around 2.8 million and 0.6 million respectively (a sparsely-populated semi-urban and rural setting) [12]. Patients $\geq 18$ years and diagnosed with OPMD by an Otorhinolaryngology specialist at our hospital were included in the study.

\section{Sample size}

A pilot study was conducted among 40 OPMD patients in the hospital, which reported the standard deviation of total costs of OPMD as 1133. A sample size of 219 was calculated using the formula $\mathrm{N}=4 \mathrm{Z}_{\alpha}^{2} \mathrm{~S}^{2} / \mathrm{W}^{2}$,[13] considering $95 \%$ confidence level $\left(Z_{\alpha}=1.96\right)$, the desired width of the confidence interval (W) as 300 , and a standard deviation (S) of 1133.

\section{Recruitment and sampling}

The principal investigator (PI-first author) enrolled patients in the study through the register maintained by the staff nurse of Otorhinolaryngology OPD. On an average day in the Otorhinolaryngology OPD of our hospital manages approximately 10-15 patients with OPMD. Every second patient was enrolled consecutively in the study. After the written informed consent procedure, the questionnaire was administered by the PI.

\section{Study tool}

The questionnaire used for the study was a validated tool of the World Health Organization (WHO) for estimating direct medical, direct non-medical and indirect costs among tuberculosis patients, which was adapted for estimating costs among OPMD patients [14].

\section{Cost survey}

The costs incurred by patients were summed up for the visits they made starting from the symptoms of OPMD till they were diagnosed or treated at our hospital (that is, till the time of interview). The costs were categorized as direct medical costs (costs for consultation, hospital admission, medicine, radiology, laboratory, and any diagnostic procedures), direct non-medical costs (costs for travel, food, and accommodation) and indirect costs. Indirect costs included patient's and accompanying member's loss of wages, and monthly family income before symptoms of OPMD minus monthly family income at the time of interview. The total costs included the sum of direct medical, direct non-medical, and indirect costs incurred by the patients for the care of OPMD. The expenditure on consuming tobacco (both smokeless as well as smoking forms) was calculated from the time they first started their consumption until the time of the interview (it was not added to any category of costs of OPMD). During the study period, on an average, one US\$ equalled 70 INR.

\section{Variables}

The primary outcome variable was the total healthcare costs incurred by OPMD patients as a continuous variable. The predictor variables were age in years, male gender, residence (rural vs. urban), years of education, occupation requiring labour, being a sole earner in the family, belonging to below poverty line family, having OSMF, time since diagnosis, time since consuming smokeless tobacco and having the first visit at a private provider.

\section{Statistical analysis}

The healthcare costs (being a continuous variable) was expressed in terms of median and interquartile range (IQR) as the skewness (4.7) and kurtosis (33.3) values suggested a lack of normality. Uni-variable linear regression analysis was performed to find out predictors to be included in the multi-variable analysis. The predictor variables with $p$-value $<0.2$ on uni-variable regression were included in the multivariable analysis. Multiple linear regression analysis was applied using the "Enter" method for finding out the significant predictors of total healthcare costs of OPMD. The difference was said to be significant when the p-value was $<0.05$.

\section{Results}

\section{Characteristics of patients}

A total of 223 eligible patients were enrolled in the study (4 patients did not agree to participate in the study). The median age of the patients was 35 (IQR 28-45) years, 78\% were male, $24 \%$ had no schooling, $75 \%$ belonged to other backward classes (OBC), 47\% were living in the rural area and $71 \%$ had an occupation requiring labour (Table 1). The median family income was Indian Rupees (INR) 15 000 (IQR 10 000-20 000), 41\% were belonging to below 
Table 1 Characteristic of patients with oral potentially malignant disorder at Bhavnagar during July-September 2019 ( $n=219)$ [one US\$ $=70$ INR]

\begin{tabular}{|c|c|}
\hline Characteristic & Number (\%) or median (IQR) \\
\hline \multicolumn{2}{|l|}{ Socio-demographic characteristic } \\
\hline Age in years & $35(28-45)$ \\
\hline Male & $170(78)$ \\
\hline Years of education & $10(8-12)$ \\
\hline \multicolumn{2}{|l|}{ Educational status } \\
\hline No schooling & $52(24)$ \\
\hline Had schooling & $167(76)$ \\
\hline Married & $174(79)$ \\
\hline \multicolumn{2}{|l|}{ Caste } \\
\hline Other backward classes (OBC) & $164(75)$ \\
\hline Scheduled caste (SC) / Scheduled tribe (ST) & $19(9)$ \\
\hline General & $36(16)$ \\
\hline Nuclear family & $108(49)$ \\
\hline Rural residence & $103(47)$ \\
\hline Occupation requiring labour & $155(71)$ \\
\hline \multicolumn{2}{|l|}{ Economic characteristic } \\
\hline Family income in Indian Rupees (INR) per month & $15000(10000-20000)$ \\
\hline Belonging to below poverty line family & $89(41)$ \\
\hline Sole earner in the family & $59(27)$ \\
\hline \multicolumn{2}{|l|}{ Tobacco consumption } \\
\hline \multicolumn{2}{|l|}{ Type of tobacco } \\
\hline Smokeless tobacco (SLT) & $193(88)$ \\
\hline Smoking & $5(2)$ \\
\hline Both type & $21(10)$ \\
\hline Age of starting SLT consumption in years & $25(20-26)$ \\
\hline Number of years of SLT consumption & $10(6-16)$ \\
\hline Number of packets of SLT per day & $3(3-5)$ \\
\hline Expenditure on SLT in INR & $6000(5400-7200)$ \\
\hline Age of starting tobacco smoking in years & $30(24-40)$ \\
\hline Number of years of tobacco smoking & $5(4-25)$ \\
\hline Number of "bidi" smoked per day & $5(5-14)$ \\
\hline Expenditure on tobacco smoking in INR & $2400(1800-3600)$ \\
\hline \multicolumn{2}{|l|}{ Type of OPMD } \\
\hline Oral submucous fibrosis (OSMF) & $168(77)$ \\
\hline Leukoplakia & $32(15)$ \\
\hline Erythroplakia & $15(7)$ \\
\hline Lichen planus & $4(2)$ \\
\hline \multicolumn{2}{|l|}{ Clinical characteristics } \\
\hline Newly diagnosed & $164(75)$ \\
\hline On treatment & $61(28)$ \\
\hline Number of months since diagnosis & $0(0-1)$ \\
\hline Number of months on treatment & $0(0-0)$ \\
\hline First visit at a private provider & $18(8)$ \\
\hline
\end{tabular}

OPMD Oral Potentially malignant disorders, INR Indian Rupees, IQR Inter-quartile range

poverty line family and $27 \%$ were sole earners in their family. The median expenditure of consuming smokeless and smoking forms of tobacco was INR 6000 (IQR 5400-7200) and INR 2400 (IQR 1800-3600) respectively.
Seventy-five percent of patients were newly diagnosed, $28 \%$ were on treatment for OPMD and $8 \%$ had first visited a private provider. 


\section{Cost burden of OPMD}

The direct medical costs incurred by patients with OPMD were low and were contributed mainly by costs for the purchase of medicines [median INR 0 (IQR 0-50)] (Table 2). The median of the direct non-medical costs was INR 150 (IQR 40-200). The travel cost to attend the health facilities [median INR 100 (IQR 40-150)] mainly accounted for the direct non-medical costs. The median indirect costs among the patients were INR 350 (IQR 250-500). The indirect costs were mainly contributed by the patient's loss of wages [median INR 200 (IQR 150-400)]. The median total costs of OPMD was INR 500 (IQR 350-750) and was mainly contributed by the indirect costs.

Table 2 Median (IQR) in Indian Rupee (INR) of costs incurred by patients with oral potentially malignant disorders at Bhavnagar during July-September $2019(n=219)$ [one US\$=70 INR]

\begin{tabular}{ll}
\hline Costs of OPMD & Median (IQR) \\
\hline Total costs & $500(350-750)$ \\
Direct medical cost & $0(0-50)$ \\
Consultation charges & $0(0-0)$ \\
Hospital admission charges & $0(0-0)$ \\
Medicine cost & $0(0-50)$ \\
Radiology cost & $0(0-0)$ \\
Laboratory cost & $0(0-0)$ \\
Procedure cost & $0(0-0)$ \\
Direct non-medical cost & $150(40-200)$ \\
Travel cost & $100(40-150)$ \\
Food cost & $50(0-100)$ \\
Accommodation cost & $0(0-0)$ \\
Indirect costs & $350(250-500)$ \\
Patient's loss of wages & $200(150-400)$ \\
Accompanying member's loss of wages & $0(0-200)$ \\
\hline
\end{tabular}

$I Q R$ inter-quartile range, OPMD Oral potentially malignant disorders

\section{Predictors of costs of OPMD}

Age in years, male gender, rural residence, being a sole earner in the family, belonging to below poverty line family, number of months since diagnosis, number of years since consuming smokeless tobacco, and having the first visit at a private provider were the variables found to have a $\mathrm{p}$-value $<0.2$ on unadjusted uni-variable linear regression analysis [see Additional file 1].

On performing multiple linear regression, rural residence, belonging to below poverty line family, being a sole earner in the family, number of months since diagnosis, and first visit at a private provider were found to be significantly predicting total costs of OPMD (Table 3 ). Rural residence, increase in one month since diagnosis and having the first visit at a private provider increased the total costs of OPMD by INR 1.2, 1.5, and 1.7 respectively. Belonging to below the poverty line family and being a sole earner in family decreased the total costs of OPMD by INR 1.2 and 1.3 respectively. The results of the regression indicated that the predictors explained $45.6 \%$ of the variance [adjusted $R^{2}=0.456, F(8,205)=23$, $\mathrm{p}<0.001]$. Age in years, male gender, and the number of years since consuming smokeless tobacco were not significantly predicting costs of OPMD.

\section{Discussion}

Patients with OPMD incurred lower direct medical and total healthcare costs when compared with their monthly family incomes in this study setting. As might be the case with patients managed at a government hospital, patients with OPMD in the present study incurred lower direct medical costs due to free diagnostic and treatment services. Over $90 \%$ of patients first visited our facility (government-run) for the management of OPMD. The low percentage of patients visiting private providers indicates their healthcare-seeking behaviour towards the public health system. Almost half of the patients resided in rural

Table 3 Multiple linear regression analysis for variables predicting total costs of OPMD at Bhavnagar during July-September 2019 $(n=219)$

\begin{tabular}{lccr}
\hline Variables & Beta-coefficients & 95\% C.l. of beta-coefficients & P-value \\
\hline Constant & 503.9 & $318.2-797.8$ & $<0.001$ \\
Age in years & 1.006 & -1.005 to 1.017 & 0.317 \\
Male gender & -1.037 & -1.226 to 1.139 & 0.665 \\
Rural residence & 1.176 & $1.029-1.345$ & 0.017 \\
Belonging to below poverty line family & -1.18 & -1.347 to -1.035 & 0.014 \\
Sole earner in family & -1.264 & -1.468 to -1.088 & 0.002 \\
Number of months since diagnosis & 1.477 & $1.353-1.612$ & $<0.001$ \\
Number of years since consuming smokeless tobacco & 1.004 & -1.012 to 1.021 & 0.591 \\
First visit at a private provider & 1.719 & $1.348-2.193$ & $<0.001$ \\
\hline
\end{tabular}

OPMD Oral potentially malignant disorders 
areas where specialist services of the private sector are scarce. Also, since three-fourth of the patients were diagnosed on the first visit when the cost survey took place, the costs for pre-diagnostic visits elsewhere were not incurred. None of the patients required hospitalization and were managed on an OPD basis, cancelling out costs of hospitalization.

The loss of wages of patients with OPMD and the travel cost for attending health facilities were the prominent costs reported in this study. Early identification and appropriate case management of OPMD would be pertinent in reducing the costs. The current study found substantially high expenditure on tobacco consumption (especially for SLT) among OPMD patients. Studies in India have documented similar expenditures on tobacco consumption in other populations as well [15-17]. Tobacco cessation activities would arrest the initiation and progression of OPMD into oral cancer, and would eventually allay current and future healthcare costs.

The present study found that rural residence, duration since diagnosis of OPMD, and having the first visit at a private practitioner increased the costs of OPMD. Patients staying in rural areas have to travel to the tertiary care centres, which are usually found in towns or cities, for the care of their OPMD complaints. Also, due to the long travel, there is a possibility of delayed careseeking and a longer duration of diagnosis since the onset of symptoms. Also, the poor accessibility to specialists in rural areas makes patients seek care at local traditional healers or quacks or private practitioners, thereby adding to the costs incurred for OPMD. These findings were supported by research on the determinants of catastrophic expenditures in patients with cancer [18-20].

We conclude that the costs of OPMD in our setting are low, however, the need for financial protection mechanisms such as universal cash transfers should be explored to overcome the direct non-medical and indirect costs. This is the first study estimating the healthcare costs of patients with OPMD in a sparsely-populated district of western India with a high caseload. Further studies are required in densely-populated urban metropolitan settings of India for estimating costs, and exploring the effects of early management, tobacco cessation, and financial protection on cost mitigation among patients with OPMD.

\section{Limitations}

There are a few inherent limitations of studies estimating costs. Since the costs are estimated based on a survey, recall bias is inherent. However, we interviewed more than $90 \%$ of patients within a month of diagnosis to avoid recall bias. We could not use any scale for assessing the severity of OPMD among the patients, which might have differentially affected the costs incurred. Also, costs incurred till the resolution of symptoms or cure or progression could not be included as we did not follow up with the patients. Our study did not employ the 'cost of illness' perspective, that is, we did not estimate the financial burden incurred by the hospital for the care of the patients. Since patients taking treatment at a private facility were not included, the study findings can be generalized only to patients being treated at government health facilities in similar semi-urban settings of India.

\section{Abbreviations \\ Cl: Confidence interval; GATS: Global Adult Tobacco Survey; INR: Indian Rupees; IQR: Interquartile range; OBC: Other backward class; OPD: Outpatient department; OPMD: Oral potentially malignant disorders; OSMF: Oral submu- cous fibrosis; PI: Principal investigator; SC: Scheduled caste; SLT: Smokeless tobacco; SPSS: Statistical Package for Social Sciences; ST: Scheduled tribe; WHO: World Health Organization.}

\section{Supplementary Information}

The online version contains supplementary material available at https://doi. org/10.1186/s13104-021-05814-2.

Additional file 1. Table showing the unadjusted linear uni-variable regression analysis for variables predicting total costs of OPMD at Bhavnagar during July-September 2019.

\section{Acknowledgements}

The authors thank Dr. Ranadip Chaudhary, Research Scientist at CHRD-SAS (New Delhi) for his advice in statistical analysis and review of the manuscript for improvements. We also thank the study participants and the Department of Otorhinolaryngology of Sir Takhtsinhji Hospital Bhavnagar for their support in the research (Dr. Vikas Sinha, Dr. Sushil Jha, Dr. Bhagirath Parmar, resident doctors and other support staff).

\section{Authors' contributions}

Both the authors contributed to conception, design, definition of intellectual content, literature search, clinical studies, data analysis, manuscript preparation, manuscript editing, and manuscript review. JRP collected the data and drafted the first draft of the manuscript. MPR reviewed and edited it for corrections. Both authors approve the final version of the article. Both authors will act as guarantors of the research.

\section{Funding}

This is a non-funded research.

\section{Availability of data and materials}

The datasets generated and/or analysed during the current study are available in the Mendeley repository, https://data.mendeley.com/datasets/kp8tnz6jzz/1.

\section{Declarations}

Ethics approval and consent to participate

Ethics approval was taken from the Ethics Committee of Government Medical College Bhavnagar, Gujarat, India (no. 877/2019). Written informed consent was taken from study participants before the interview.

Consent for publication

Not applicable.

Competing interests

The authors declare that they have no competing interests. 


\section{Author details}

${ }^{1}$ Department of Community Medicine, Government Medical College Bhavnagar (Maharaja Krishnakumarsinhji Bhavnagar University), Near ST bus stand, Jail Road, Bhavnagar, Gujarat 364001, India. Division of Clinical Epidemiology, ICMR-National Institute of Occupational Health ( $\mathrm{NIOH})$, Meghani Nagar, Ahmedabad, Gujarat 380016, India.

Received: 26 July 2021 Accepted: 15 October 2021

Published online: 24 October 2021

\section{References}

1. Manne RK. Oral potentially malignant disorders/individuals. Oral Oncol. 2014;50:e7-8. https://doi.org/10.1016/j.oraloncology.2013.10.021.

2. Warnakulasuriya $S$, Johnson NW, Van Der Waal I. Nomenclature and classification of potentially malignant disorders of the oral mucosa. J Oral Pathol Med. 2007;36:575-80.

3. Mello FW, Miguel AFP, Dutra KL, Porporatti AL, Warnakulasuriya S, Guerra ENS, et al. Prevalence of oral potentially malignant disorders: a systematic review and meta-analysis. J Oral Pathol Med. 2018;47:633-40. https://doi. org/10.1111/jop.12726

4. Pahwa V, Nair S, Shetty RS, Kamath A. Prevalence of oral premalignant lesions and its risk factors among the adult population in Udupi Taluk of coastal Karnataka, India. Asian Pac J Cancer Prev. 2018;19:2165-70. https://doi.org/10.22034/APJCP.2018.19.8.2165.

5. Pratik P, Desai VD. Prevalence of habits and oral mucosal lesions in Jaipur, Rajasthan. Indian J Dent Res. 2015;26:196-9.

6. Mehrotra R, Pandya S, Chaudhary AK, Kumar M, Singh M. Prevalence of oral pre-malignant and malignant lesions at a tertiary level hospital in Allahabad, India. Asian Pac J Cancer Prev. 2008;9:263-5. https://doi.org/ 10.4103/2277-8632.128484

7. Srivastava R, Sharma L, Pradhan D, Jyoti B, Singh O. Prevalence of oral premalignant lesions and conditions among the population of Kanpur City, India: a cross-sectional study. J Fam Med Prim Care. 2020;9:1080. https:// doi.org/10.4103/jfmpc.jfmpc_912_19.

8. Ni Riordain R, Christou J, Pinder D, Squires V, Hodgson T. Cost of illness of oral lichen planus in a UK population — a pilot study. J Oral Pathol Med. 2016:45:381-4.

9. Thomson PJ. Potentially malignant disorders-the case for intervention. J Oral Pathol Med. 2017;38:42-9. https://doi.org/10.1111/jop.12626.

10. Aguilar RR, Antonio J, Saucedo M, Martínez ST. Financial risk of increasing the follow-up period of breast cancer treatment currently covered by the Social Protection System in Health in México. Cost Eff Resour Alloc. 2018. https://doi.org/10.1186/s12962-018-0094-y.

11. Ventura-Alfaro CE, Torres-Mejía G, Ávila-Burgos LD. Hospitalization and mortality in Mexico due to breast cancer since its inclusion in the catastrophic expenditures scheme. Salud Publica Mex. 2016;58:187-96.

12. Registrar General of India. Ministry of Home Affairs. Government of India. Census of India 2011 — district census handbook Bhavnagar: primary census abstract. New Delhi: Government of India; 2011. https://censusindia. gov.in/2011census/dchb/2414_PART_B_DCHB_BHAVNAGAR.pdf.

13. Hulley S, Cummings S, Browner W, Grady D, Newman T. Designing clinical research: an epidemiologic approach. 4th ed. Philadelphia, PA: Lippincott Williams \& Wilkins; 2013.

14. World Health Organization. Tuberculosis patient cost surveys: a handbook (Annex 1: generic survey instrument). Geneva: WHO Press, Geneva, Switzerland; 2017.

15. Tata Institute of Social Science (TISS) Mumbai and Ministry of Health and Family Welfare. Government of India. Global Adult Tobacco Survey GATS 2. Mumbai; 2017.

16. Rupani MP, Parikh KD, Kakadia MJ, Pathak MM, Patel MR, Shah MA. Crosssectional study on smokeless tobacco use, awareness and expenditure in an urban slum of Bhavnagar, western India. Natl Med J India. 2019;32:137-40. https://doi.org/10.4103/0970-258X.278686.

17. Schensul JJ, Nair S, Bilgi S, Cromley E, Kadam V, Mello SD, et al. Availability, accessibility and promotion of smokeless tobacco in a low-income area of Mumbai. Tob Control. 2013;22:324-30. https://doi.org/10.1136/tobac cocontrol-2011-050148.

18. Doshmangir L, Yousefi M, Hasanpoor E, Eshtiagh B, Haghparast-Bidgoli $H$. Determinants of catastrophic health expenditures in Iran: a systematic review and meta-analysis. Cost Eff Resour Alloc. 2020;18:1-21. https://doi. org/10.1186/s12962-020-00212-0.

19. Kimman M, Jan S, Yip CH, Thabrany H, Peters SA, Bhoo-Pathy N, et al. Catastrophic health expenditure and 12-month mortality associated with cancer in Southeast Asia: results from a longitudinal study in eight countries. BMC Med. 2015;13:190. https://doi.org/10.1186/s12916-015-0433-1.

20. Leng A, Jing J, Nicholas S, Wang J. Catastrophic health expenditure of cancer patients at the end-of-life: a retrospective observational study in China. BMC Palliat Care. 2019;18:1-10.

\section{Publisher's Note}

Springer Nature remains neutral with regard to jurisdictional claims in published maps and institutional affiliations.
Ready to submit your research? Choose BMC and benefit from:

- fast, convenient online submission

- thorough peer review by experienced researchers in your field

- rapid publication on acceptance

- support for research data, including large and complex data types

- gold Open Access which fosters wider collaboration and increased citations

- maximum visibility for your research: over $100 \mathrm{M}$ website views per year

At BMC, research is always in progress.

Learn more biomedcentral.com/submissions 